\author{
Military Technical College \\ Kobry El-Kobbah, \\ Cairo, Egypt
}

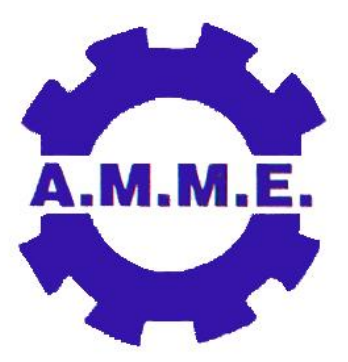

14th International Conference on

Applied Mechanics and

Mechanical Engineering.

\title{
Simulation of Solar Desalination System Operating at Reduced Pressure
}

By

Elsayed E. Allam*

Ayman G. M. Ibrahim*

Salman E. Elshamarka*

\begin{abstract}
:
The increase of population worldwide makes the availability of fresh water an important issue especially for developing countries. Fortunately, most of the developing countries are characterized by a high intensity of solar radiation. The solar desalination using the free energy supply from the sun is promising option to reduce the operating cost for the desalination plant. In this study a simulation of water desalination system using solar energy and operates at sub-atmospheric pressure is presented. The system consists of a solar basin connected to an air cooled condenser and utilizes natural means-atmospheric pressure and gravity-to develop a vacuum condition. The system requires simple technology with less number of problems and can be used anywhere as low maintenance and no skilled workers are needed. The simulation results under the meteorological conditions of Cairo, Egypt indicated significant improvements in the system efficiency and daily water productivity of the present system compared with conventional solar techniques.
\end{abstract}

\section{Keywords:}

Desalination, Solar energy, Sub-atmospheric pressure, Egypt climate and Simulation 
* Egyptian Armed Forces

\section{Introduction:}

There is increasing demand of fresh water due to population growth and rapid increase of agricultural and industrial activities. One way of meeting this demand is desalination of the saline water. There are several desalination methods like reverse osmosis, electro dialysis, vapor compression, multistage flash distillation, and multiple-effect distillation. However, these processes usually consume significant amount of energy. Many countries in the world, particularly those suffering from severe water shortages, cannot afford the energy required for desalination. Fortunately, many of those countries lie in areas with high solar insolation rates.

Basically, solar desalination is used in nature to produce rain, which is the main source of fresh water supply on Earth. Provided efficient technologies are developed, solar desalination can be a suitable choice to utilize the solar energy in a cost-effective way.

The most widely used solar desalination system is a simple solar still, where the heat collection and distillation processes take place in the same equipment. However, the main disadvantage of the solar still is its low efficiency, which is $35 \%$ (maximum) and daily freshwater production is about $2-3 \mathrm{~L} / \mathrm{m}^{2}$, under the Egyptian climatic conditions [1]. Evaporation at a low temperature under vacuum conditions, leads to a good improvement in the system efficiency as energy losses are reduced when water is evaporated at lower temperature and with less energy requirements. In the presence of vacuum the effect of non condensable gases which reduce the rate of condensation is also avoided. High system productivity from solar desalination systems operating under atmospheric pressure were reported elsewhere, [2, 3].

Desalination system operating at reduced pressure using natural forces of gravity and atmospheric pressure was first proposed by Al-Kharabsheh et. al. [4, 5]. This new concept has the advantages of vacuum distillation without requiring additional energy to create the vacuum. An electric water heater was used to supply the hot water at $60^{\circ} \mathrm{C}$, assuming that in real life the unit will be supplied with its energy requirements from a solar collector. The experimental results showed that the system efficiency may reach 80 $\%$.

Gude et. al. [6] used a 12-volt DC heater powered by grid power to drive desalination system operating at low evaporation pressure. Results of this study showed that efficiency of $69 \%$ can be sustained at evaporation temperatures of $40^{\circ} \mathrm{C}$. Further, they investigated a modified system driven by low-grade heat sources to maintain the evaporation temperature at $50^{\circ} \mathrm{C},[7,8]$. Heat rejected by the condenser of an absorption refrigeration unit is used as a source to drive the proposed desalination system with efficiency of $80-90 \%$.

Natural vacuum desalination (NVD) system powered by renewable energy was studied by Ayhan et. al. [9]. A pilot unit of the NVD system was built to demonstrate the working principle. System tests were performed to estimate the production rate of distilled water on the basis of the climatic data of Bahrain.

In Egypt, there is great demand for potable water due to population and improvement in standard of living. Egypt has already exhausted her fixed Nile water share, and the 
groundwater requires expensive energy to abstract more and costs to transport. Horizontal expansion, especially in remote areas either for agriculture or other purposes, is a must for many social, economic, environmental, strategic and other reasons. Desalination might be the proper way of water supply in ride areas expansions. However, desalination uses significant amount of energy, today mostly from fossil fuels. It is, therefore, reasonable to rely on renewable energy sources such as solar energy. Egypt is one of the sun belt countries. In 1991, a solar atlas for Egypt was issued, concluding that the yearly direct solar radiation intensity ranges between $1900 \mathrm{~kW} . \mathrm{hr} / \mathrm{m}^{2}$ in the north and $2800 \mathrm{~kW} . \mathrm{hr} / \mathrm{m}^{2}$ in the south and the sun shine duration ranges between 9-11 hr/d, with very few cloudy days, [10]. Under these situations, solar stills are highlighted as desalinators for low-capacity fresh water demand, less than $200 \mathrm{~m}^{3} / \mathrm{d}$, since other desalination plants are uneconomical, [11, 12].

The present study investigates solar desalination under sub-atmospheric conditions, where a vacuum is created in a way proposed by Al-Kharabsheh et. al. [4, 5]. Modification is proposed, whereby solar energy is used directly to produce distillate in the solar basin. The simulation of this modified system is developed to demonstrate its feasibility and predict the performance under the meteorological conditions of Cairo, Egypt.

\section{System Principle of Operation:}

The desalination system analyzed in this study makes use the vacuum that is created by balancing hydrostatic and atmospheric pressures in the supply and discharge pipes. The evaporation chamber has provisions to feed the cold saline water directly to the chamber and collect solar energy as well as disposing the concentrated brine. The evaporation chamber is connected to a condenser, which dissipates the heat of condensation to the environment.

The vapor pressure of seawater is about $1.84 \%$ less than that of fresh water in the temperature range of $0-100^{\circ} \mathrm{C}$, [5]. In order to maintain the distillation of potable water, vapor pressure of the saline water must be kept above that of the fresh water, which is done by increasing the temperature of saline water. A temperature differential of about $15^{\circ} \mathrm{C}$ is adequate to overcome the vapor pressure differential and drives this distillation process. This temperature differential can be achieved using solar energy.

As saline water in the evaporator starts evaporating, its salinity increases which tends to decrease evaporation rate, so it becomes necessary to withdraw the concentrated brine at a certain flow rate and inject new saline water at a rate equivalent to the withdrawal plus evaporation rates. The withdrawn water will be at a temperature equal to that of the evaporator, so it becomes necessary to recover the energy from it. A tube-in-tube heat exchanger is used for this purpose, where saline water flows inside the inner tube and withdrawn water will flow in the annulus in a counter-current direction. Under the influence of vacuum conditions at the saline water surface in the evaporator, saline water can be injected by the atmospheric pressure; hence no pumping power is required.

\section{Description of the System:}

A schematic arrangement of the proposed system is shown in Figure (1). Components of this system include an evaporation chamber, a natural draft condenser, heat exchanger, and three barometric columns. These three columns serve as the saline water column, the waste withdrawal column and the freshwater column, each with its own constant- 
level holding tank. These holding tanks are installed at ground level while the evaporator is installed top of the saline water and waste withdrawal columns at the barometric height of $10 \mathrm{~m}$ above the free surface in the holding tanks. The top of the freshwater column is connected to the outlet of the condenser. Water vapor will flow from the evaporator to the condenser where it will condense and flow into the freshwater column. By maintaining constant levels in the holding tanks with suitable withdrawal rates of waste and fresh water, this configuration enables the desalination process to be run without any mechanical energy input for fluid transfer or holding the vacuum. The dimensions of various components are given as follows.

The evaporator is a solar still with cross section area of $0.25 \mathrm{~m}^{2}$ and $0.4 \mathrm{~m}$ height sloped by $30^{\circ}$ to be $0.1 \mathrm{~m}$. The evaporator's top surface is a glass sheet to allow solar energy transmission to the base of the evaporator. Meanwhile, the evaporator base is covered by a selective black coating. The evaporator has a provision for saline water supply, through a $0.012 \mathrm{~m}$ pipe. A pipe of $0.012 \mathrm{~m}$ is connected to double pipe heat exchanger to withdraw the concentrated brine. The top $0.9 \mathrm{~m}$ of the inner pipe is fabricated from copper and enclosed by $0.025 \mathrm{~m}$ pipe. The condenser is $0.1 \mathrm{~m}$ copper tube of $0.5 \mathrm{~m}$ length and $0.001 \mathrm{~m}$ thickness. On its lateral surface, 10 fins of $0.254 \mathrm{~m}$ outer diameter and $0.001 \mathrm{~m}$ thickness are soldered $0.04 \mathrm{~m}$ apart. The other end of the condenser is connected to a condensate receiver via $0.012 \mathrm{~m}$ pipe. All pipes are fabricated from polypropylene, unless otherwise is mentioned.

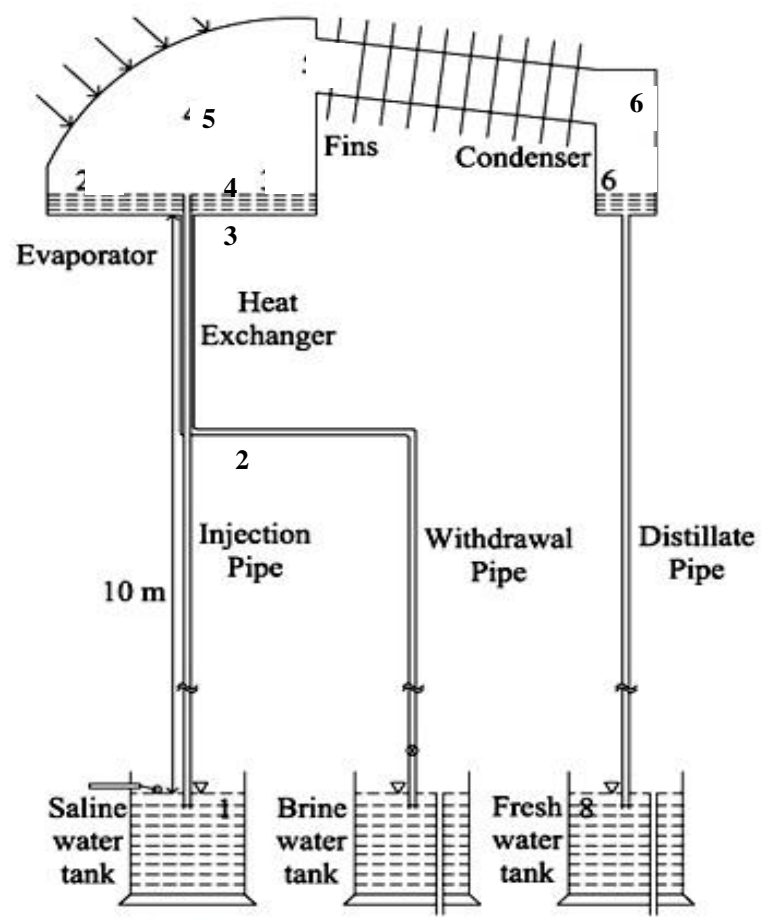

Fig(1): Schematic of the proposed system

The various processes throughout the system are such that:

1-2: Isothermal pressure drop $\left(T_{a}=\right.$ const. $)$ in the injection pipe.

2-3: Heat addition process of the saline water to injection temperature, $\mathrm{T}_{\mathrm{i}}$, in the heat exchanger.

3-4: Isobaric ( $P_{w}=$ const.) heat addition process to withdrawal temperature, $T_{w}$, in the evaporator chamber.

4-5: Evaporation process at constant temperature $\left(T_{w}=\right.$ const.) in the evaporator chamber. 
5-6: Condensation process at constant temperature ( $T_{c}=$ const.).

6-7: Isobaric heat rejection ( $\mathrm{P}_{\mathrm{f}}=$ const.).

7-8: Isothermal pressure increase $\left(T_{f}=\right.$ const.).

\section{Mathematical Model Development:}

The mathematical model developed by Al-Kharabsheh et. al. [13] for a solar desalination system powered by PV panel was modified such that the evaporator chamber utilizes directly the thermal energy of the solar radiation. The solar still has a curved glass cover to withstand the stresses due to pressure difference. The following assumptions are used:

- Steady state conditions are prevailed.

- The heat capacity of glass cover, evaporator and condenser materials is negligible.

- The amount of water condensate on the glass cover of evaporator chamber is taken as fraction of the condensate in the condenser according to surface area ratio.

- No heat transfer from the piping throughout the system.

- Uniform temperature throughout the system.

- No change in ambient temperature around the day.

- The effect of the glass cover curvature on the solar still inclination is neglected.

Under these assumptions the resulting system of equations describing the physical model of desalination system is described below.

\subsection{Calculation of solar energy input}

To start desalination, supply of heat is required, which goes to preheat the feed, evaporate the water, and to compensate for the heat losses. This heat is supplied by solar energy which is the sum of hourly terrestrial direct normal and diffuse solar radiation on inclined surface. The solar energy input $\mathrm{I}_{t}$ is given by: 


$$
I_{t}=I_{\text {oh }}\left(T_{b+} T_{d}\right) \cos (\theta)
$$

where the hourly solar radiation $\mathrm{I}_{\text {oh }}$ is calculated from [14].

\subsection{Evaporation chamber}

The overall water and salt mass balances within the evaporator chamber are:

$$
\begin{array}{r}
\dot{m}_{\mathrm{i}}=\dot{m}_{\mathrm{w}}+\dot{m}_{\mathrm{fc}}+\dot{m}_{\mathrm{fg}} \\
\dot{m}_{\mathrm{i}} \mathrm{C}_{\mathrm{i}}=\dot{m}_{\mathrm{w}} \mathrm{C}_{\mathrm{w}}
\end{array}
$$

The energy balance equations within the evaporator chamber are as follows:

- For the evaporator

$$
\begin{array}{r}
\mathrm{A}_{\mathrm{g}} \mathrm{l}_{\mathrm{t}}+\dot{m}_{\mathrm{i}} \mathrm{C}_{\mathrm{pi}} \mathrm{T}_{\mathrm{i}}=\dot{m}_{\mathrm{w}} \mathrm{C}_{\mathrm{pw}} \mathrm{T}_{\mathrm{w}}+\dot{m}_{\mathrm{fc}}\left(\mathrm{h}_{\mathrm{fg}}+\right. \\
\left.\mathrm{C}_{\mathrm{pw}} \mathrm{T}_{\mathrm{w}}\right)+\dot{m}_{\mathrm{fg}} \mathrm{C}_{\mathrm{pw}} \mathrm{T}_{\mathrm{w}}+Q_{\text {loss }}
\end{array}
$$

- For glass cover

$$
\begin{gathered}
\alpha_{g} A_{g} l_{t}+\dot{m}_{f g} h_{f g}+\varepsilon_{\text {eff }} \sigma \\
A_{g}\left(\left(T_{w}+273\right)^{4}-\left(T_{g}+273\right)^{4}\right)= \\
\varepsilon_{g} \sigma A_{g}\left(\left(T_{g}+273\right)^{4}-\right. \\
\left.\left(T_{a}+273\right)^{4}\right)+(2.8+3 w) A_{g}\left(T_{g}-T_{a}\right) \\
(5) \quad \text { For seawater interface } \\
\dot{m}_{f t}\left(h_{f g}+C_{p w} T_{w}\right)+\varepsilon_{\text {eff }} \sigma A_{b}\left(\left(T_{w}+\right.\right. \\
\left.273)^{4}-\left(T_{g}+273\right)^{4}\right)=k_{w} A_{b}\left(T_{b}-T_{w}\right) / \\
d_{w}
\end{gathered}
$$

- For black base

$$
\begin{array}{r}
\alpha_{b} T_{g} A_{b} I_{t}=\left(T_{b}-T_{a}\right) A_{b} /\left(\left(t_{e} / k_{e}\right)+\left(t_{\text {ins }} /\right.\right. \\
\left.\left.k_{\text {ins }}\right)+\left(1 / h_{\text {Nub }}\right)\right)+k_{w} A_{b}\left(T_{b}-T_{w}\right) / d_{w}
\end{array}
$$

The evaporation rate per unit area is determined from [15]:

$$
\begin{aligned}
& \qquad \dot{v}_{\mathrm{e}}=\left(\alpha_{\mathrm{m}} / \rho_{\mathrm{f}}\right)\left[\mathrm{f}(\mathrm{c}) \mathrm{P}_{\mathrm{Tw}} /\right. \\
& \left.\left(\mathrm{T}_{\mathrm{w}}+273\right)^{0.5}-\mathrm{P}_{\mathrm{Tf}} /\left(\mathrm{T}_{\mathrm{f}}+273\right)^{0.5}\right] \\
& (8)
\end{aligned}
$$

The distillate water condensate on the glass cover is assumed as:

$\dot{m}_{\mathrm{fg}}=\dot{m}_{\mathrm{fc}}\left(\mathrm{A}_{\mathrm{g}} / \mathrm{A}_{\mathrm{t}}\right)$

(9)

The heat losses from the bottom and side walls of the evaporator are calculated using equations (10) and (11):

$$
Q_{b}=h_{\text {Nub }} A_{b}\left(T_{s b}-T_{a}\right)
$$




$$
Q_{s}=h_{\text {Nus }} A_{s}\left(T_{s s}-T_{a}\right)
$$

Where the convective heat transfer coefficients are determined from [16] for the bottom, $h_{\mathrm{Nu}, \mathrm{b}}$, and [17] for the side walls, $\mathrm{h}_{\mathrm{Nu}, \mathrm{s}}$.

The heat interaction at the glass cover includes the reflected fraction of solar radiation and heat transfers by convection and radiation from glass cover to ambient. The convective heat transfer coefficient based on wind velocity is obtained from [18]. The total heat dissipation from the glass cover is estimated as follows:

$$
\begin{aligned}
Q_{g}=\varepsilon_{g} \sigma A_{g}\left(\left(T_{g}+273\right)^{4}-\left(T_{a}+273\right)^{4}\right) \\
+(2.8+3 w) A_{g}\left(T_{g}-T_{a}\right)+r_{g} A_{g} I_{t}
\end{aligned}
$$

\subsection{Heat exchanger}

The injection pipe, which carries seawater to the evaporator, is coaxial and internal to the withdrawal pipe. So, major part of the energy of withdrawn water can be recovered. The heat exchanger duty $Q_{h}$ is estimated based on NTU method, [16]. The temperature of the water entering the evaporator was calculated by:

$\left(\mathrm{Q}_{\mathrm{h}} / \dot{m}_{\mathrm{i}} \mathrm{C}_{\mathrm{po}}\right)+\mathrm{T}_{\mathrm{o}}$

$$
\mathrm{T}_{\mathrm{i}}=
$$

\subsection{Condenser}

The heat of evaporation will mainly be dissipated to the environment by the condenser during vapor condensation and the rest will be carried away by fresh water produced. So the condenser duty is given as, [17]:

$\left(h_{f g}+0.68 C_{p f}\left(T_{w}-T_{i f f}\right)\right)$

$$
\mathrm{Q}_{\mathrm{c}}=\dot{m}_{\mathrm{fc}}
$$

The condensation heat transfer coefficient is larger than free convection heat transfer coefficient from the outside surface of the condenser. As vapor velocity is small and condensation rate is low, the condensate flows as a thin annular film inside the tube. 
The average film heat transfer coefficient is given by, [16]:

$$
\begin{array}{r}
h_{c}=\underset{ }{0} \\
\left.\left.\left(T_{w}-T_{i f f}\right)\right)\right]^{1 / 4}
\end{array}
$$

The convective heat transfer coefficient for the cylinder and fin surface given by [19]:

$h_{\text {Nuf }}=\left(k_{\mathrm{a}} / \mathrm{S}\right)\left\{\left(R \mathrm{Ra}_{\mathrm{s}} / 12 \pi\right)[2-\exp (-(\mathrm{cl}\right.$ $\left.\left.\left.\left./ \mathrm{Ra}_{\mathrm{s}}\right)^{3 / 4}\right)-\exp \left(-\beta\left(\mathrm{cl} / \mathrm{Ra}_{\mathrm{s}}\right)^{3 / 4}\right)\right]\right\}$ where, $\zeta=d_{c} / d_{f}, \beta=0.17 \zeta+\exp (-$ $4.8 \zeta)$ and $\mathrm{cl}=\left[23.7-1.1\left(1+152 \zeta^{2}\right)^{0.5}\right.$ $[1+\beta]^{4 / 3}$

Hence, the rate of heat transferred from condenser surface area can be calculated as:

$$
Q_{c}=\left(h_{\text {tip }} N A_{f, \text { tip }} \eta_{f}+h_{c} N A_{f, \text { sides }} \eta_{f}+h_{c}\right.
$$
$\left.A_{b}\right)\left(T_{c}-T_{a}\right)$

\subsection{Performance indices}

The performance of the desalination system will be assessed based on the total productivity of distillate water and the thermal efficiency which are defined by equations (18) and (19), respectively

$\dot{m}_{\mathrm{ft}}=\dot{m}_{\mathrm{fc}}+\dot{m}_{\mathrm{fg}}$

(18)

$=\dot{m}_{\mathrm{ft}} \mathrm{h}_{\mathrm{fg}} / \mathrm{Q}_{\mathrm{in}}$ 


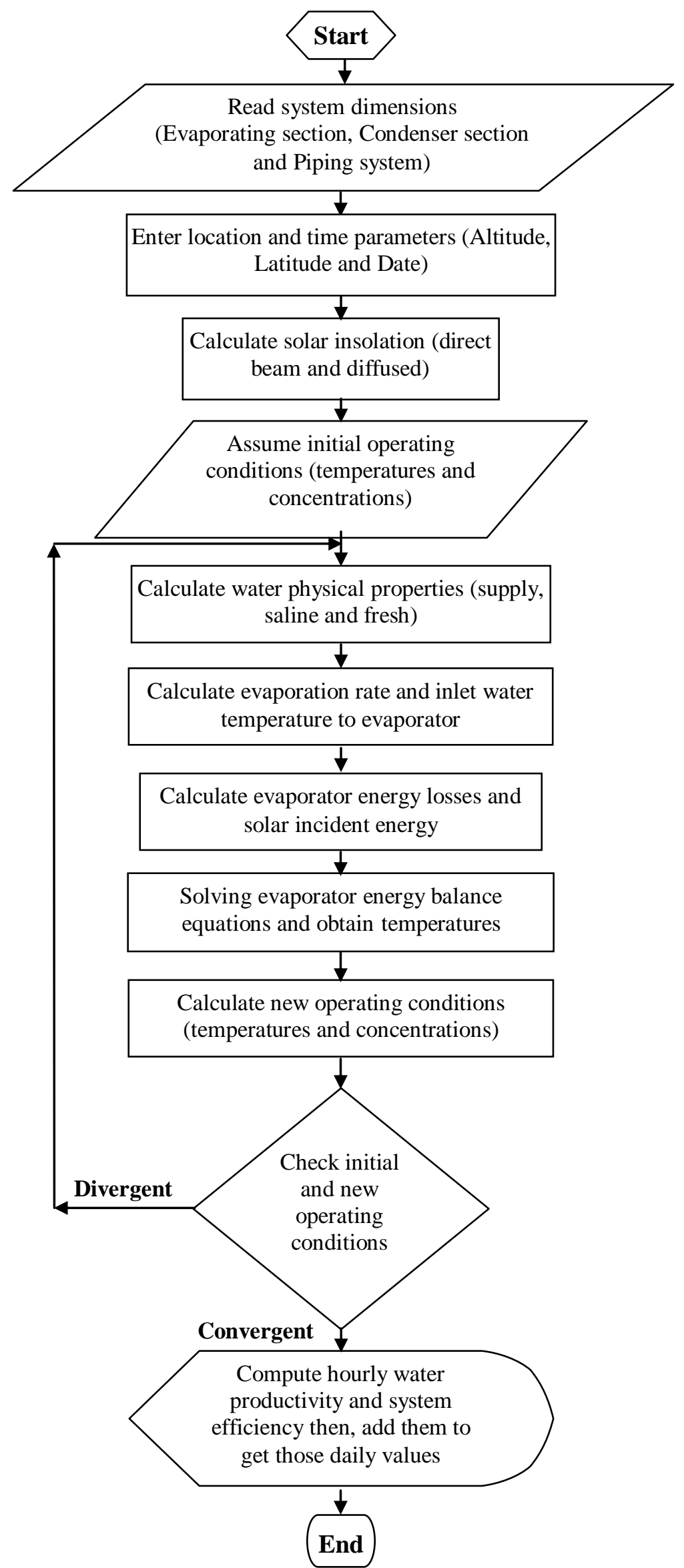

Fig (2): Flow chart of the program 
The equations of mathematical model presented in the above section are employed in Matlab $^{\circledR}$ and solved numerically. Figure (2) shows the flow chart of the computer program which indicates sequence of computation and convergence algorithm. The simulations were carried out for the climatic conditions of Cairo, Egypt (latitude $30.05 \mathrm{~N}$, longitude $31.25 \mathrm{E}$ ). The inlet temperature of the saline water was assumed as the ambient. The initial saline water concentration was taken as $3.5 \%$. The properties of air and water were calculated from correlations given by [13] and [20], respectively. The simulation results for the aforementioned system specifications and dimensions are presented in Figures (3-14).

The solar insolation profiles for four typical days in January, April, July and October are shown in Figure (3). The maximum received solar insolation is $933 \mathrm{~W} / \mathrm{m}^{2}$ and obtained in April, at 1 $\mathrm{pm}$. The variation of the total energy losses from solar still is shown in Figure (4). It is noted that, the profile of total energy losses persists for all seasons and matching the profile of received solar insolation.

The hourly variation on the base temperature of the solar still is shown in Figure (5). The base temperature exhibits peak values corresponding to the mid-day peak in solar radiation due to neglected thermal inertia of solar still structure. One of the key variables in the system is the water temperature inside the solar still $\left(T_{w}\right)$. Higher $T_{w}$ demands higher energy requirements to satisfy the sensible and the latent heat loads. Meanwhile, low $T_{w}$ results in smaller solar still size, shorter startup time, lower scaling and corrosion rates. Predicted results of $T_{w}$, is illustrated in Figure(6). For example, when the base temperature is $120^{\circ} \mathrm{C}$ 
in April at $1 \mathrm{pm}$, the saline water temperature will be about $65{ }^{0} \mathrm{C}$ at saline water inlet temperature of $36.4^{\circ} \mathrm{C}$.

Saline water concentration inside the evaporator increases as fresh water produced and periodic flushing is required to prevent scale formation which reduces absorptivity of solar still base and hence the efficiency. Figure (7) shows the hourly variation of water salinity inside the solar still while keeping the saline water level constant at $4 \mathrm{~cm}$. A similar trend exists with respect to the saline water feed to the system. Figure (8) shows that the saline water feed increases with the increase of the received solar insolation.

The hourly freshwater productivity is illustrated in Figure (9). As indicated, the freshwater productivity increases with the increase of solar insolation. For example, the output in April increases from $0.01 \mathrm{~L} / \mathrm{hr}$ at $7 \mathrm{am}$ to 0.2 $\mathrm{L} / \mathrm{hr}$ at $1 \mathrm{pm}$, then decreases till the end of sunlight duration. Figure (10) shows the daily variation of freshwater productivity which is minimum in January and July and maximum in April and October.

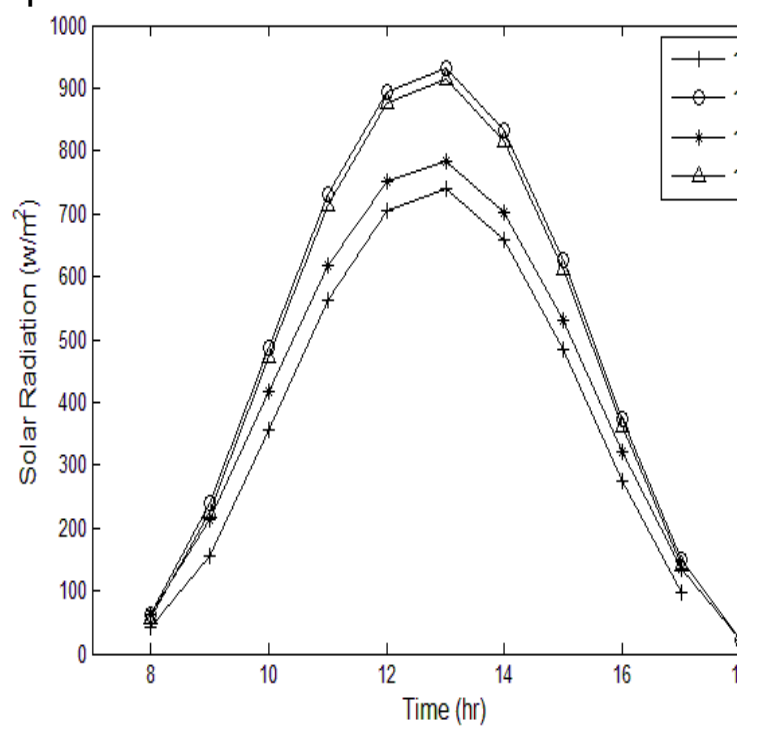




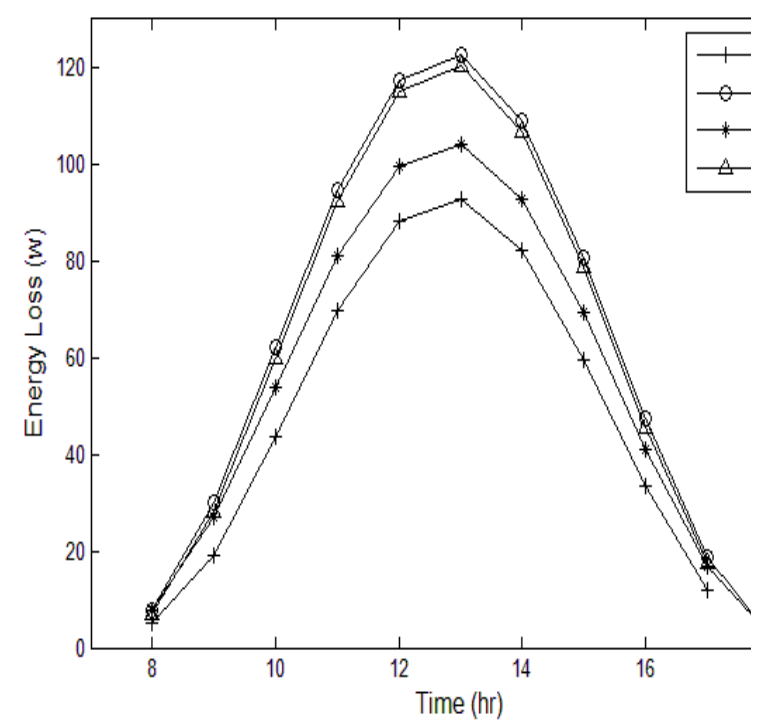

Fig (3): Hourly variation of solar insolation. Fig (4): Hourly variation of energy loss.
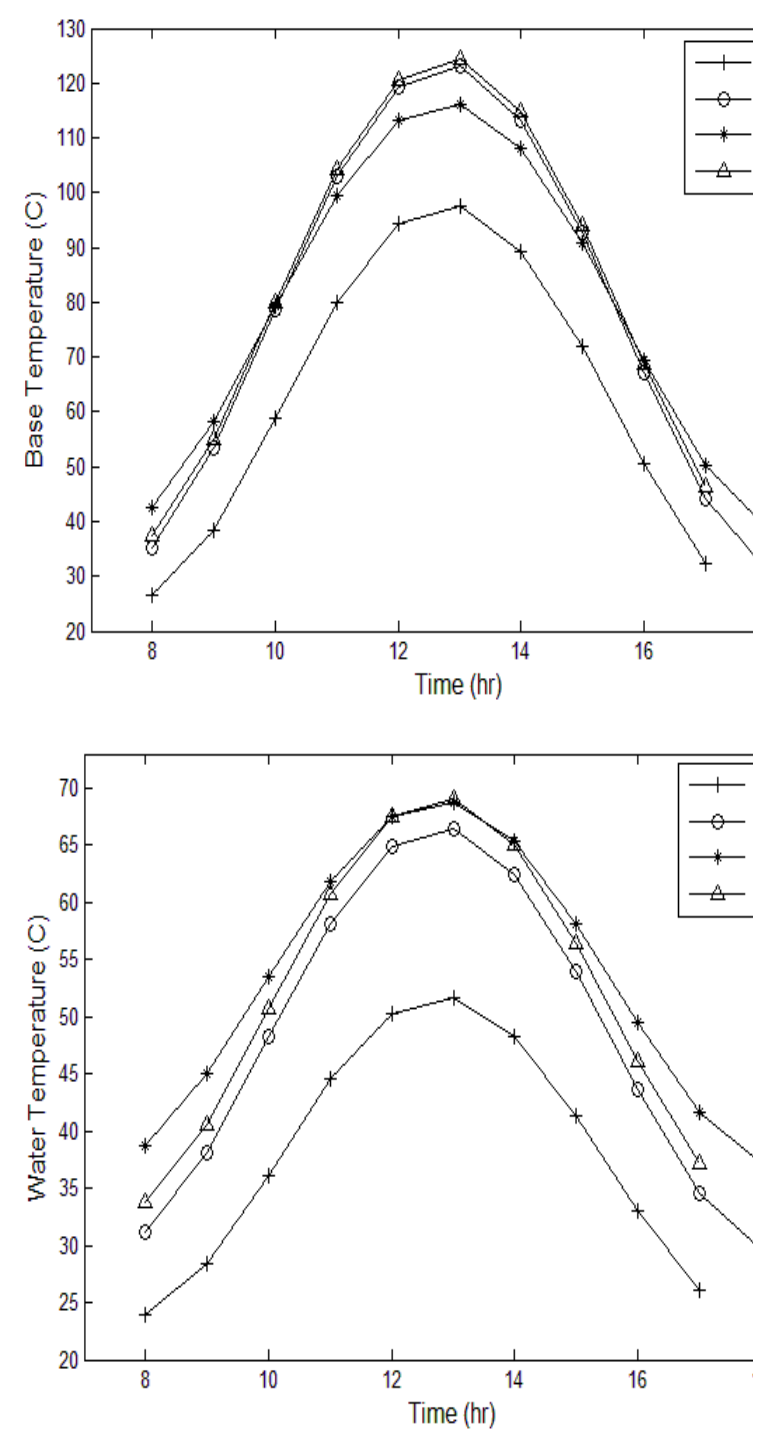

Fig (5): Hourly variation of base temp.

Fig (6): Hourly variation of water temp. 

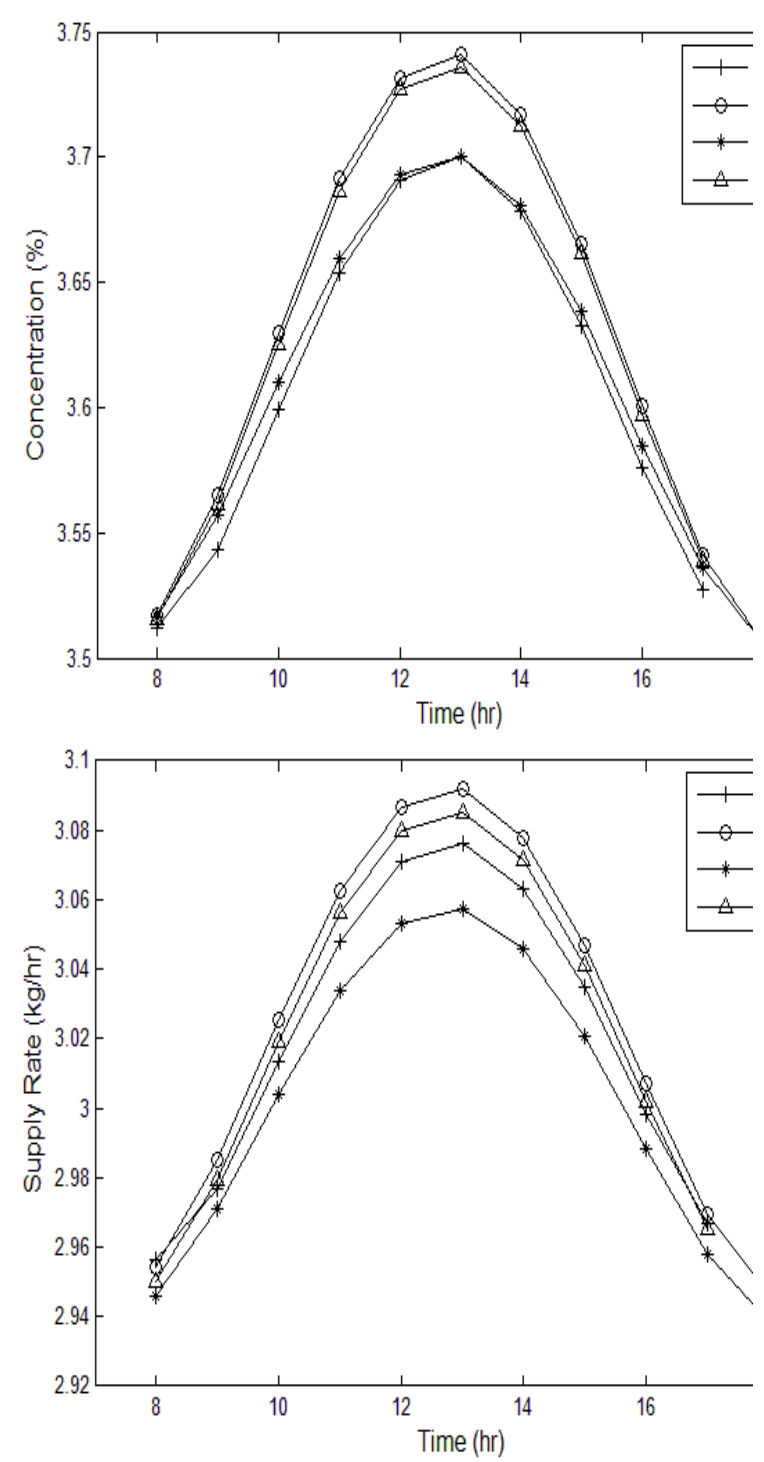

Fig (7): Hourly variation of concentration. Fig (8): Hourly variation of supply rate.

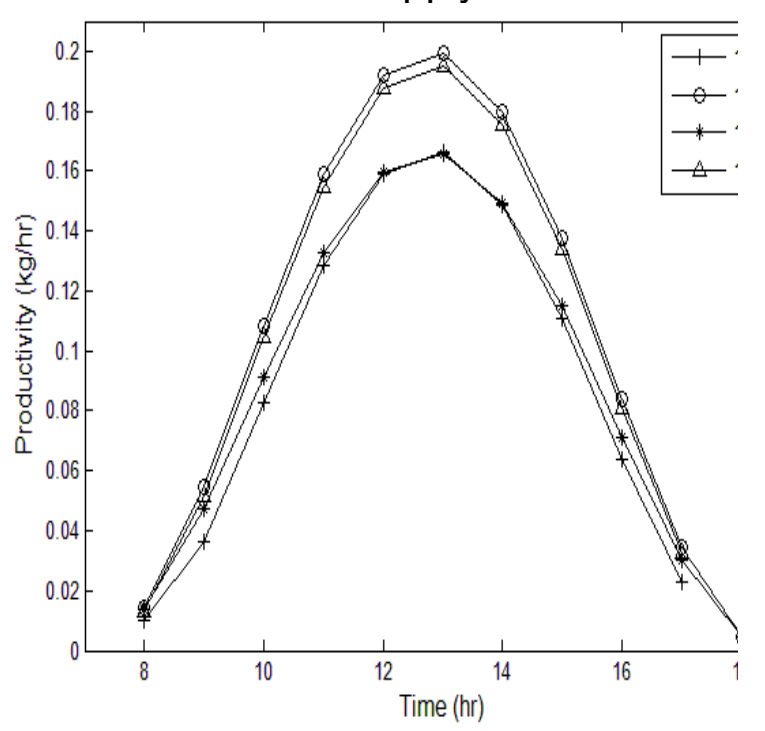




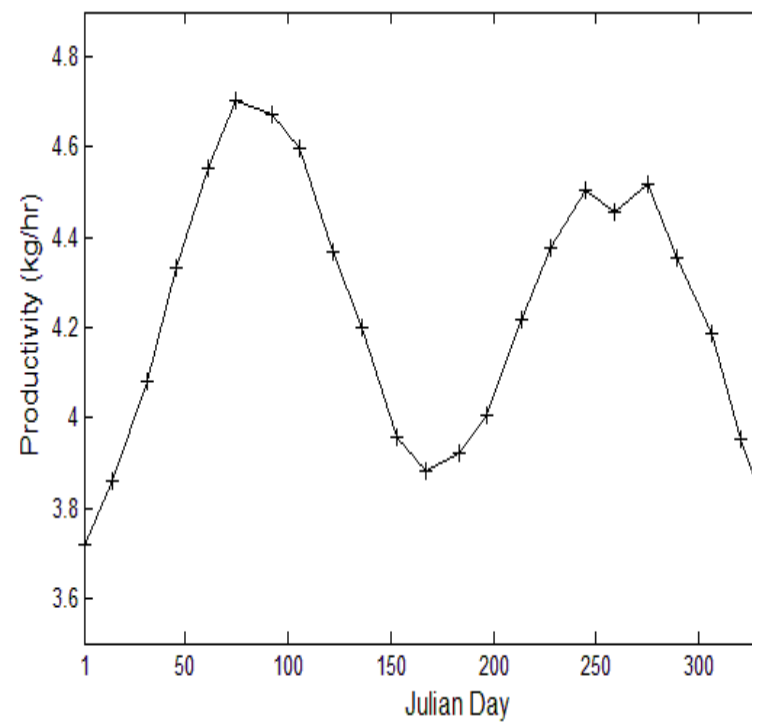

Fig (9): Hourly variation of productivity.

Fig (10): Annually variation of productivity.
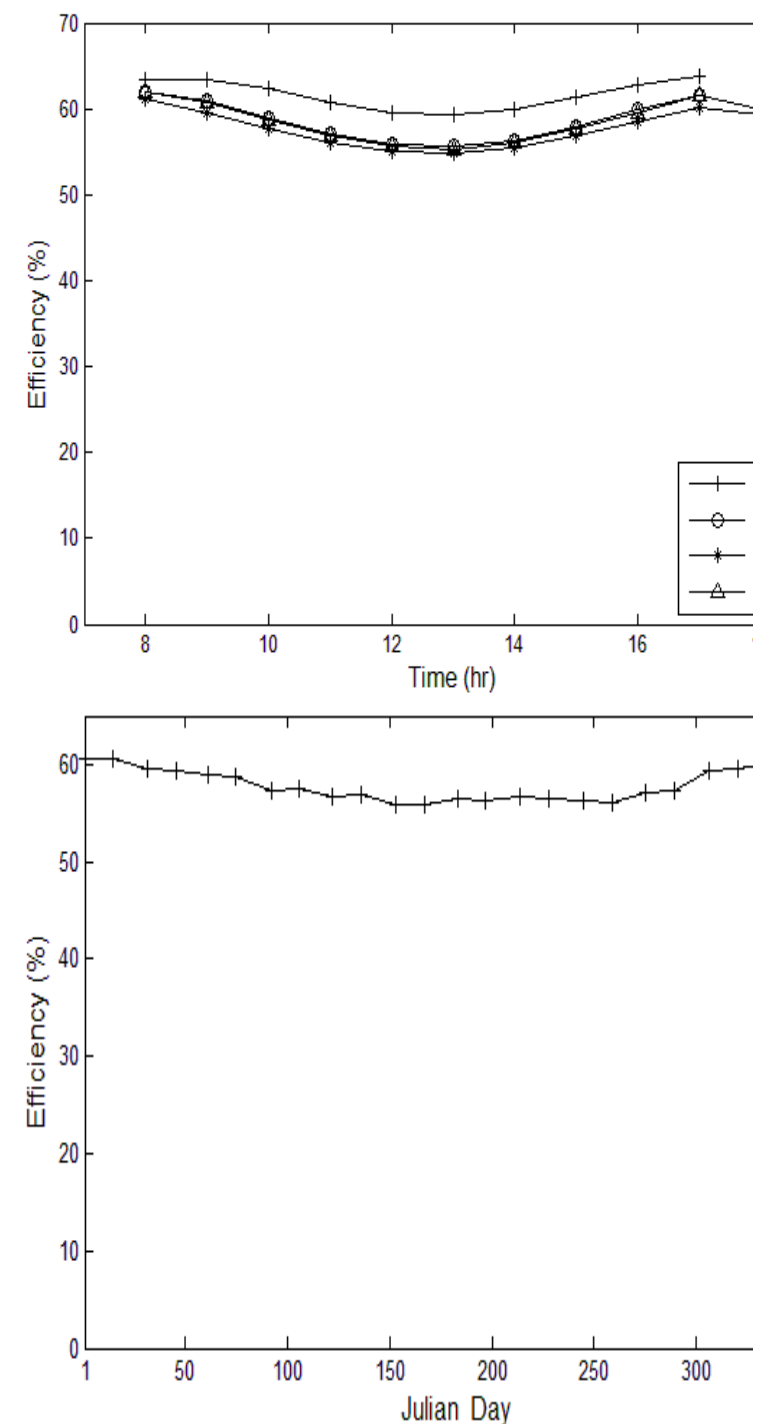

Fig (11): Hourly variation of efficiency.

Fig (12): Variation of average daily 
efficiency.
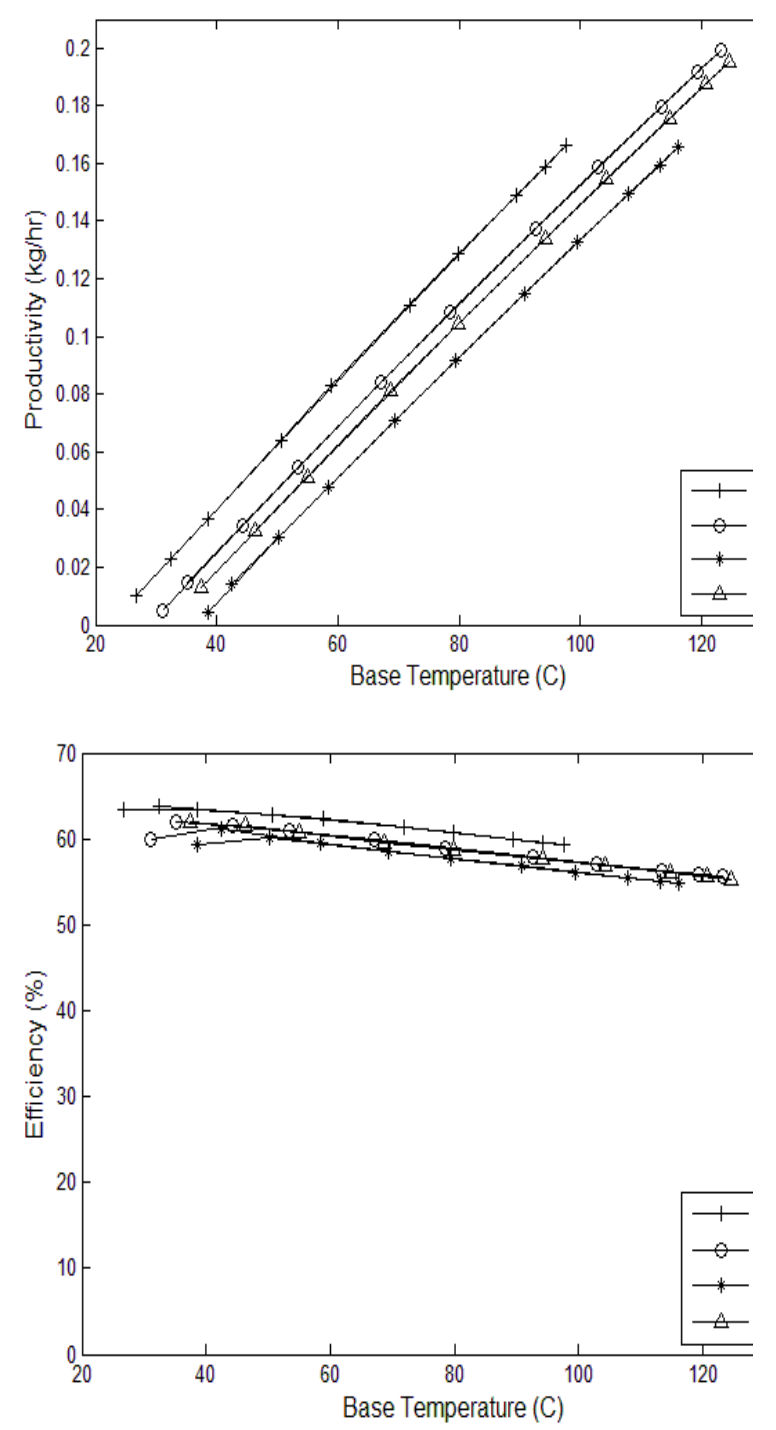

Fig (13): Productivity variation with base temp Fig (14): Efficiency variation with base temp

Simulation results of the system efficiency are shown in Figure (11). Even though the freshwater production increases as the evaporation temperature increases, the specific energy consumption also increases. Hence, the sensible heat demand and the total energy losses increase, resulting in higher specific energy consumption. Consequently, the higher system efficiency is achieved in January, $63.8 \%$ at 5 p.m, which has the lowest ambient temperature. Figure (12) shows the daily system efficiency. In general, its value is 
around $60 \%$ with a little drop in hot days due to high energy losses.

Additional simulation results are presented in Figures (13) and (14), where the effect of base temperature on the system performance. The fresh water productivity increases as the base temperature increases. The maximum water productivity at given base temperature is recognized at January. On the other hand, system efficiency decreases with the increase of base temperature due to increase of energy losses.

As summary, the simulation results of the system performance showed that the maximum daily water productivity was obtained in April of $4.77 \mathrm{~L} / \mathrm{m}^{2}$ while the minimum of $3.66 \mathrm{~L} / \mathrm{m}^{2}$ was in December. As compared to 2-3 L/d. $\mathrm{m}^{2}$ from a conventional flat-basin solar still [1], an improvement of about $40 \%$ is achieved for the vacuum operated solar still. Also, the maximum daily efficiency of proposed system was in January of $60.7 \%$ while the minimum of $55.6 \%$ was in September. Hence, an average improvement in performance of $47 \%$ is achieved compared with that for the conventional still whose efficiency may reach $35 \%$ in the best operating conditions, [1].

\section{Conclusions:}

In this study simulation of a solar still operating under natural vacuum conditions was conducted. The simulation was run for the climatic conditions of Cairo, Egypt. The results of hourly water productivity, thermal efficiency and temperature variations for four typical days in January, April, July and October were presented. The daily variation of water productivity and system efficiency were predicted, as well. The maximum daily fresh water output and system efficiency could reach $4.77 \mathrm{~L}$ per unit of evaporator base area and $60.7 \%$, respectively. The study proved the feasibility of the present desalination system in Egypt climate and its potential to produce higher quantity of freshwater compared with a simple flat basin solar still for the same input and evaporator area. The system can be scaled for large-scale applications where the height of the columns remains the same irrespective of the scale of the system. An experimental test rig for validation of the simulation results is under progress. 


\section{References:}

[1] Zeinab S. Abdel-Rehim, Ashraf Lasheen; "Experimental and theoretical study of a solar desalination system located in Cairo, Egypt"; Desalination 217 (2007) 52-64

[2] Abu-Jabal M.S., Kamiya I. and Narasaki Y., Proving test for a solar-powered desalination system in Gaza-Palestine, Desalination, 137 (2001) 1-6.

[3] Jubran B.A., Ahmed M.I., Ismail A.F. and Abakar Y.A., Numerical modeling of a multi-stage solar still, Energy Conversion and Management, 41 (2002) 1107-1121.

[4] Al-Kharabsheh S. and Goswami D.Y., Analysis of an innovative water desalination system using low-grade solar heat, Desalination, 156 (2003) 323-32.

[5] Al-Kharabsheh S. and Goswami D.Y., Experimental study of an innovative solar water desalination system utilizing a passive vacuum technique, Solar Energy, 75 (2003) 395-401.

[6] Gude V.G. and Khandan N.N., Desalination at low temperatures and low pressures, Desalination, 244 (2009) 239-247.

[7] Gude V.G. and Khandan N.N., Desalination using low-grade heat sources, ASCE Journal of Energy Engineering, 134 (2008) 95-101.

[8] Gude V.G. and Khandan N.N., Combined desalination and solar assisted air conditioning system, Energy Conversion and Management, 49 (2008) 3326-3330

[9] Ayhan T. and Al Madani H., Feasibility study of renewable energy powered seawater desalination technology using natural vacuum technique, Renewable Energy, 35 (2010) 506-514.

[10] M. Shaltout, Egyptian Solar Radiation Atlas, Geography Institute, Cairo, Egypt, 1998.

[11] G.N. Tiwari, H.N. Singh, Rajesh Tripathi, Present status of solar distillation, Solar Energy, 75 (2003) 367-373.

[12] Kalogirou S.A., Seawater desalination using renewable energy sources, Progress in Energy and Combustion Science, 31 (2005) 242-281.

[13] Al-Kharabsheh S. and Goswami D.Y., Theoretical analysis of a water desalination system using low-grade solar heat, ASME Journal of Solar Energy Engineering, 126 (2004) 774-780

[14] Moustafa M. Elsayed, Ibrahim S. Taha and Jaffar A. Sabbagh, Design of solar thermal system, Scientific Publishing Center, 1994, Saudi Arabia.

[15] Bemporad G.A., Basic hydrodynamic aspects of a solar energy based desalination process, Solar Energy, 54 (1995) 125-134.

[16] Holman J.P., Heat transfer, McGraw Hill, 2001, New York.

[17] Lienhard J.H. IV and Lienhard J.H. V, A heat transfer textbook, Phlogiston Press, 2006, Cambridge.

[18] El-Sebaii A.A., Aboul-Enein S. and El-Bialy E., Single basin solar still with baffle suspended absorber, Energy Conversion and Management, 41 (2000) 661-675.

[19] Rohsenow W.R., Hartnett J.P. and Cho Y.I., Handbook of heat transfer, Third edition, McGraw-Hill, 1998.

[20] H. El-Dessouky and H. Ettouney, Fundamentals of salt water desalination, Elsevier, 2002, The Netherlands.

\section{Nomenclatures}
A Area $\left(\mathrm{m}^{2}\right)$
C Solute concentration (\%)
$\mathrm{C}_{\mathrm{p}} \quad$ Specific heat $\left(\mathrm{J} / \mathrm{kg} .{ }^{\circ} \mathrm{C}\right)$
d Diameter $(\mathrm{m})$, Depth $(\mathrm{m})$ 
$f(c) \quad$ Correction factor (dimensionless)

g Gravitational acceleration $\left(\mathrm{m} / \mathrm{s}^{2}\right)$

h Convection heat transfer coefficient $\left(\mathrm{W} / \mathrm{m}^{2} . K\right)$

$\mathrm{h}_{\mathrm{fg}} \quad$ Latent heat of vaporization $(\mathrm{J} / \mathrm{kg})$

$\mathrm{h}_{\mathrm{fgm}}$ Modified latent heat of condensation $(\mathrm{J} / \mathrm{kg})$

I Incident solar radiation $\left(\mathrm{W} / \mathrm{m}^{2}\right)$

k Thermal conductivity $(\mathrm{W} / \mathrm{m} . \mathrm{K})$

$\mathrm{m}$ Mass flow rate $(\mathrm{kg} / \mathrm{s})$

$\mathrm{N} \quad$ Number of fins

P Pressure $\left(\mathrm{N} / \mathrm{m}^{2}\right)$

Q Heat transfer rate (W)

$r \quad$ Reflectivity (dimensionless)

Ra Rayleigh number (dimensionless)

$\mathrm{S}$ Distance between two successive fins $(\mathrm{m})$

$\mathrm{T}$ Temperature $\left({ }^{\circ} \mathrm{C}\right)$

$\mathrm{t}$ Thickness $(\mathrm{m})$

$v \quad$ Evaporation rate per unit area $(\mathrm{m} / \mathrm{s})$

w Wind velocity $(\mathrm{m} / \mathrm{s})$

\section{Greek Letters:}

a Absorptivity (dimensionless)

$\alpha_{m} \quad$ Empirical coefficient $\left(10^{-7}-10^{-6} \mathrm{~kg} / \mathrm{m}^{2}\right.$.Pa.s. $\left.\mathrm{K}^{0.5}\right)$

$\varepsilon \quad$ Emissivity (dimensionless)

$\eta \quad$ Efficiency (\%)

$\theta \quad$ Solar incidence angle $(\stackrel{\circ}{)})$

v Kinematic viscosity $(\mathrm{m} / \mathrm{s})$

$\rho$ Density $\left(\mathrm{kg} / \mathrm{m}^{3}\right)$

$\sigma \quad$ Stefan-Boltzman constant $\left(5.67 \times 10^{-8} \mathrm{~W} / \mathrm{m}^{2} \mathrm{~K}^{4}\right)$

$\mathrm{T} \quad$ Transmittance for solar radiation (dimensionless)

\section{Subscripts:}

a Ambient, Air

b Bottom, Direct beam solar radiation

c Condenser

d Diffuse solar radiation

e Evaporation

f Fresh water, Fin

g Glass cover

h Hour, Heat exchanger

i Injection pipe

$i_{f} \quad$ Interface of film condensation

in Input

ins Insulation

I Liquid

- Reference state

s Surface, Side

$\mathrm{t}$ Total 
Proceeding of the $14^{\text {th }}$ AMME Conference, 25 -27 May 2010

v Vapor

w Withdrawal pipe, Saline water in evaporator 